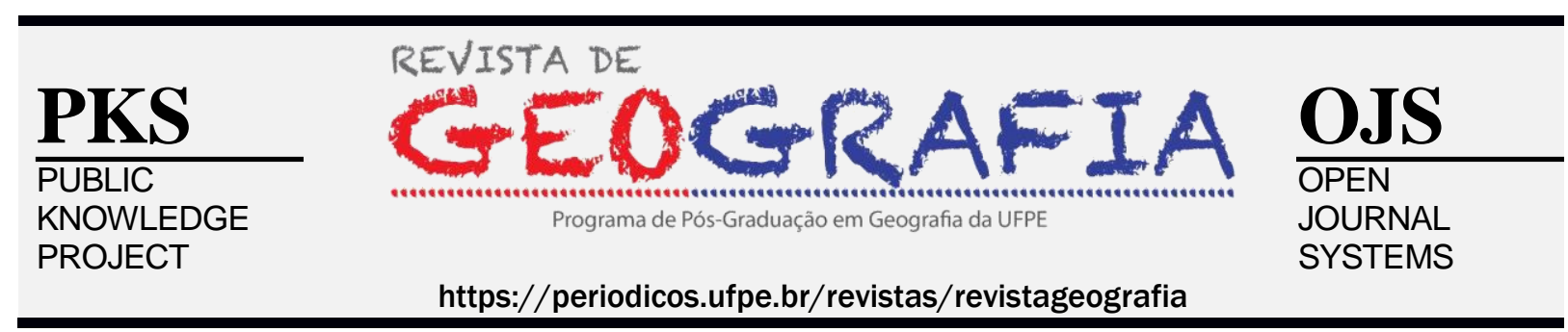

\title{
MODERNIZAÇÃO DA AGRICULTURA: TERRA E ÁGUA NO ESPAÇO AGRÁRIO CEARENSE
}

\author{
Alexsandra Maria Vieira Muniz ${ }^{1}$ \\ ${ }^{1}$ Profa.Dra. do Departamento de Geografia, Pesquisadora do Observatório das Metrópoles, \\ Coordenadora do Pibid-Geografia, Univseridade Federal do Ceará. Email:geoalexsandra@gmail.com
}

Artigo recebido em 29/12/2018 e aceito em 24/11/2019

\begin{abstract}
RESUMO
O objetivo do presente artigo é evidenciar as consequências do processo de modernização da agricultura no Ceará, entendendo-a como resultante da intensificação das relações capitalistas que vem agravando questões atinentes a terra e a água no espaço agrário cearense. Como metodologia tivemos a pesquisa bibliográfica, documental e estatística, bem como, trabalhos de campo. Com a posterior sistematização e análise do material coletado foi possível constatar a persistência da acirrada concentração fundiária e o desigual uso dos recursos hídricos.

Palavras-chave: Agricultura Cearense, Modernização da Agricultura, Estrutura Fundiária, Recursos Hídricos.
\end{abstract}

\section{MODERNIZATION OF AGRICULTURE: EARTH AND WATER IN CEARÁ'S AGRARIAN SPACE}

\begin{abstract}
The objective of this article is to highlight the consequences of the process of modernization of agriculture in Ceará, understanding it as a result of the intensification of capitalist relations that is aggravating issues related to land and water in Ceará's agrarian space. As methodology we had the bibliographical, documentary and statistical research, as well as fieldwork. With the subsequent systematization and analysis of the collected material it was possible to verify the persistence of the fierce concentration of land and the unequal use of water resources.
\end{abstract}

Keywords: Agriculture Cearense, Modernization of Agriculture, Land Structure, Water Resources 


\section{Introdução}

Considerando que o agravamento das questões atinentes à terra e água no território cearense tem intrínseca relação com a forma como vem se desenvolvendo as relações de produção capitalistas no campo. Evidenciamos tal processo através da política de modernização agrícola, tendo como base autores como Silva(1994;1981); Sorj(1980); LIMA(2000); (GONÇALVES NETO, 1997), DELGADO, 1985), (MULLER, 1989; e ELIAS, 1999, 2002). Tendo como recorte o território cearense, dentro da política de modernização delimitamos a política de irrigação em diferentes contextos de atuação até chegar nos dias atuais.

Assim, tendo como pressuposto que a problemática que envolve a questão da água e da terra no espaço agrário vem sendo agravada pelo modo como têm se expandido as relações capitalistas de produção objetivamos fazer um resgate de como vem se dando tal processo para em seguida tecer algumas considerações diante dos fatos a serem analisados a partir da delimitação espaço temporal que se delineia na sequencia.

A Metodologia envolveu procedimentos essenciais da pesquisa científica, tais como, trabalhos de campo, pesquisa estatística, pesquisa bibliográfica e documental, tendo como recorte espacial o Estado do Ceará e temporal notadamente os anos de 1990 até o presente. Com esta metodologia apresentamos alguns resultados além desta introdução e das considerações finais na sequencia deste artigo.

\section{Resultados}

A agricultura cearense que no contexto do Nordeste brasileiro até a década de 1960, conforme relatou Silva (1994), permaneceu sem grandes transformações no conjunto de sua agropecuária, fazendo parte do exército de reserva de lugares (SANTOS, 1993), sempre apontado como uma região problema, dada a sua vulnerabilidade aos riscos climáticos e aos problemas trazidos pela seca, ganha atenção especial dentro da política do governo no combate à desigualdade regional, embora isto tenha acontecido dentro de uma realidade histórica dependente economicamente da região Sudeste.

Vale destacar neste contexto o acirrado debate teórico sobre a "questão agrária", relacionada fundamentalmente com a necessidade do desenvolvimento das regiões atrasadas.

No Brasil, o modelo desenvolvimentista adotado durante o período do "milagre econômico", fundamentando-se na Cepal considerava a industrialização como o caminho mais 
rápido para superar a condição do subdesenvolvimento da América Latina, centrando o debate nos entraves colocados pelo atraso da agricultura e pela estrutura agrária em favor de uma política voltada para o desenvolvimento industrial.

O modelo desenvolvimentista brasileiro encarava o atraso da agricultura como um empecilho ao desenvolvimento do capitalismo, sendo que o principal argumento era que a arcaica estrutura agrária brasileira, centrada no latifúndio, não responderia à demanda urbano/industrial.

A discussão envolve, de um lado o pensamento liberal conservador, que defendia uma "modernização sem reforma" da agricultura, através da introdução do progresso técnico na produção agrícola, e de outro, autores marxistas e estruturalistas, para os quais, a modernização da agricultura deveria passar por uma reforma da estrutura agrária.

Os primeiros defendiam que o "dualismo produtivo" - setor arcaico e moderno - existente no campo brasileiro seria progressivamente eliminado pela difusão dos avanços tecnológicos. Não haveria, desse modo, obstáculos insuperáveis ao desenvolvimento. As estruturas produtivas não "tipicamente capitalistas" seriam absorvidas e retransformadas pelo avanço da racionalidade econômica no campo. Os estímulos de preços, crédito e de assistência técnica seriam poderosas forças para induzir a agricultura a executar as funções requeridas, sem passar por mudanças na estrutura agrária, especialmente na propriedade rural.

A agricultura brasileira marcada por um modelo desenvolvimentista adotado com ênfase na industrialização permitiu a intensificação das relações econômicas tipicamente capitalistas, resultando no desenvolvimento e materialização dessas relações através da instauração de uma nova base técnica de produção, já que é no início dos anos sessenta, que corresponde ao final da fase de industrialização pesada no Brasil, que se instauram as indústrias de máquinas e insumos agrícolas, datando o início da chamada Revolução Verde, que permitiu um uso mais intensivo da terra e da força de trabalho, o que em outras palavras significou a subsunção do trabalho agrícola ao capital ou nas palavras de Silva (1981:25) " a dominação do capital sobre o processo de trabalho".

Destarte, “... o desenvolvimento das relações de produção capitalistas no campo se faz 'industrializando' a própria agricultura” (Silva, 1994:14). Assim, o processo de modernização se dá através de uma série de apropriações parciais, descontínuas do trabalho rural, possibilitada pela difusão das inovações mecânicas, físico-químicas, e biológicas (SILVA, 1981). 
Dessa forma, as condições sociais e técnicas da estrutura agrária se efetivaram a partir de um papel ativo do Estado, na medida em que este impulsionou a modernização da agricultura, através da criação de inúmeras políticas públicas.

Nesse contexto, ganha destaque especialmente em meados dos anos sessenta, que data da necessidade de "uma política de integração da economia nordestina às novas necessidades do planejamento econômico-financeiro definido para o País" (LIMA, 2000, p. 46) a ideia de irrigar o Nordeste que começou a despertar o interesse público desde a década de 1940, com as primeiras tentativas de se levar o benefício da irrigação ao semi-árido pelo Departamento Nacional de Obras Contra as Secas (Dnocs), através da construção de grandes açudes e canais de irrigação.

A intervenção Estatal, inicialmente, se deu com a criação em 1952 do Banco do Nordeste do Brasil - BNB e em 1956 de um Grupo de Trabalho para o Desenvolvimento do Nordeste o GTDN, liderado por Celso Furtado.

Tendo como base a elaboração de um diagnóstico da região Nordeste, o GTDN teve como proposta, a industrialização como fator dinamizador do desenvolvimento do Nordeste, considerada como a grande indutora da modernização, passando a ser vista como a solução para absorver o contigente de mão-de-obra, além de promover uma consequente integração nacional.

Para executar os planos do GTDN, é instituída em 1959, a Superintendência de Desenvolvimento do Nordeste - SUDENE que tinha como objetivo "reorientar a economia nordestina através da expansão industrial e agrícola (esta última viabilizada através de uma reforma agrária e projetos de colonização)" (SORJ, 1980, p.96).

Neste percurso, a década de 1970 despontou como marco importante no direcionamento das políticas de caráter centralizador-desconcentrador, foi neste período que data do surgimento do I Plano Nacional de Irrigação, ligado à política federal intitulada Programa de Integração Nacional (PIN), que o governo inaugurou uma nova forma para atacar o problema do Nordeste rural, onde as políticas de irrigação passaram a ser prioridade.

Os perímetros irrigados no Nordeste e, por extensão, no Ceará, que, por sua vez, são signos da modernização agrícola, foram os instrumentos utilizados para atingir os objetivos da política de irrigação e em última instância "solucionam" uma questão política e outra econômica - política - porque se faz tabula rasa para a questão da reforma agrária, já que com esses projetos de colonização argumenta-se que está sendo colocada em prática a "reforma agrária”, porque se distribuem terras aos pequenos produtores, trabalhadores rurais, rendeiros 
e parceiros, mas na verdade o número de beneficiados é extremamente restrito em relação ao universo da população rural - econômica - porque ao mesmo tempo que se implementa a modernização nos perímetros, se conserva a estrutura arcaica circundante a estes.

Foram construídos no Ceará nove ${ }^{1}$ dos vinte e sete (27) perímetros instalados na região Nordeste e como o Vale do Jaguaribe estava entre as áreas selecionadas para introdução da política de irrigação, convém destacar que dos nove perímetros localizados no Ceará, quatro foram instalados na região do Baixo Jaguaribe, especificamente nos municípios de Morada Nova, Jaguaruana, Limoeiro do Norte e Russas, o que mostra ser esta região palco das parcerias do capital público e privado.

Nestas condições, caracterizada, até então, por uma agricultura predominantemente rudimentar e por um baixo perfil tecnológico, a região do Baixo Jaguaribe passa por uma mudança no seu sistema de produção a partir da década de 1970, período que marca a primeira fase do processo de modernização nesta região quando se deu a implantação pelo DNOCS dos perímetros públicos de irrigação Morada Nova (1970) e Jaguaruana (1977), frutos da política de modernização agrícola, baseada no desenvolvimento da agricultura irrigada que se destinava à agricultura familiar, tendo como objetivo a transformação desta em agricultura capitalista produtora de mercadorias passando, toda sua dinâmica a estar subordinada à lógica da produção capitalista, cujo objetivo é a acumulação e a valorização de capital.

Ao mesmo tempo em que o Estado cria esses locus privilegiados de reprodução do capital onde se concentram os recursos econômicos fazendo surgir novos atores, ele também preserva os já existentes - por exemplo, o latifundiário - nas fronteiras e mesmo dentro destes perímetros.

A modernização da agricultura permitiu um uso mais intensivo da terra e da água. Por outro lado, no tocante a estrutura fundiária cearense é notável ao analisar os dados dos censos agropecuários das ultimas décadas que persiste a histórica concentração fundiária, senão vejamos:

$\begin{array}{lrrrr}\begin{array}{l}\text { Tabela 01: Número e área dos estabelecimentos do Estado do Ceará segundo grupos de área total - } 2017 \\ \text { Grupos de área total(ha) }\end{array} & \text { Número de Estabelecimentos } & \text { Área dos Estabelecimentos (ha) } \\ & \text { Frequencia } & \% & \text { Frequencia } & \% \\ \text { Total } & 394317 & 100 \% & 6895413 & 100 \% \\ \text { Menos de 1 } & 89549 & 22,71 \% & 41938 & 0,61 \% \\ 1 \text { a menos de } 10 & 194884 & 49,42 \% & 532895 & 7,73 \% \\ 10 \text { a menos de } 50 & 58990 & 14,96 \% & 1362424 & 19,76 \%\end{array}$

\footnotetext{
${ }^{1}$ Os Perímetros Públicos Irrigados tiveram como primeira materialização o Projeto Bebedouro. Morada Nova, Forquilha, Paraipaba, Várzea do Boi, Quixabinha, Icó-Lima Campos, Banabuiú e Jaguaruana são estruturadas para receber os capitais novos.
} 
Revista de Geografia (Recife) V. 36, No. 2, 2019

$\begin{array}{lrrrr}50 \text { a menos de } 100 & 13942 & 3,54 \% & 951890 & 13,80 \% \\ 100 \text { a menos de } 500 & 11464 & 2,91 \% & 2204806 & 31,97 \% \\ 500 \text { a menos de } 1.000 & 1670 & 0,42 \% & 1734401 & 25,15 \% \\ \text { De } 1.000 \text { A Mais de } 1.000 & 6 & 0,05 \% & 67060 & 0,97 \% \\ \text { Produtor sem área } & 23608 & 5,99 \% & & 0,00 \%\end{array}$

Fonte: Censo Agropecuário do IBGE, 2017

Pela Tabela 01 temos ao analisar a distribuição dos estabelecimentos segundo estratos de área que $72,13 \%$ dos estabelecimentos possuem menos de 10 ha, representando apenas 8,34\% da área total. Já os estabelecimentos com mais de 100 ha, constituem 3,38\% do total dos estabelecimentos e representam 58,09\% da área total.

Já fazendo um comparativo com os censos de 1996 e de 2006 pudemos observar, que no ano de 1996 72,32\% dos estabelecimentos agropecuários possuem menos de 10 ha representando, entretanto, apenas 7,07\% da área total. Já os estabelecimentos com mais de 100 ha constituem 5,22\% do total dos estabelecimentos e representam 65,24\% da área total. No ano de 2006, a situação de concentração da posse da terra aumentou, pois o número de estabelecimentos com menos de 10 ha foi elevado $(75,40 \%)$ enquanto que a área dos mesmos foi reduzida (6,74\%). Em contrapartida, os estabelecimentos com mais de 100 ha foram reduzidos para 4,54\%, mantendo praticamente o percentual de área estável (64,66\%).

Este quadro de concentrada estrutura fundiária tem intensificado os conflitos por terra. Uma análise mais detalhada pode ser vista no trabalho de Sampaio e Rafael (2016), como também no de Matos e Alencar (2016).

O conceito de conflito por terra definido pela própria CPT (Comissão Pastoral da Terra) é:

\begin{abstract}
Ações de resistência e enfrentamento pela posse, uso e propriedade da terra e pelo acesso a seringais, babaçuais ou castanhais, quando envolvem posseiros, assentados, quilombolas, geraizeiros, indígenas, pequenos arrendatários, pequenos proprietários, ocupantes, sem-terra, seringueiros, camponeses de fundo de pasto, quebradeiras de coco babaçu, castanheiros, faxinalenses, etc (CPT, 2017, p.16).
\end{abstract}

Conforme Barreira e Paula(1998) os conflitos que sempre estiveram presentes no processo de formação do espaço agrário cearense em decorrência da alta concentração de terra existente no Estado tem se intensificado nos últimos anos com: implementação de grandes projetos ligados a mineração; instalação de parques eólicos; instalação de cativeiros de 
carcinicultura; grandes projetos de irrigação e; megaprojetos de apoio estrutural através de grandes obras públicas.

A irrigação utiliza mais intensivamente a água que o solo. Quanto a distribuição do consumo de água para diferentes usos segundo a Agência Nacional de Água(ANA): 69\% dos recursos hídricos é voltado para irrigação, $12 \%$ para animais, 10\% para uso urbano, $7 \%$ para uso industrial e $2 \%$ para uso Rural.

A Carcinicultura é uma das atividades mais demandadoras de água. Segundo dados da Organização das Nações Unidas(ONU), para se criar um quilograma de camarão em cativeiro, são necessários de 50 a 60 mil litros de água.

Como bem relata o documento elaborado pela Comissão Pastoral da Terra: As perspectivas do Uso da Água e dos Solos no Brasil- O Futuro do Agro e Hidronegócio, é

uma contradição com a própria Lei Brasileira de Recursos Hídricos - particularmente no Nordeste, onde se utiliza esse volume de água para criar um produto de exportação enquanto grande parte da população não tem sua cota diária de água para satisfazer suas necessidades básicas.

$\mathrm{Na}$ cidade de Aracati o grande empreendimento são as fazendas de camarões, com destaque para a empresa Compescal que tem várias unidades espalhadas pela cidade. Esta atividade tem trazido inúmeras consequências, sendo uma delas a salinização dos solos.

A ONU já apresentou dados da agricultura irrigada no mundo inteiro, onde 80 milhões de hectares, de um total de 260 milhões, estão salinizados ou degradados, particularmente nas regiões áridas e semi-áridas.

Segundo dados da Agência Nacional de Águas (ANA) o Brasil cultiva aproximadamente 60 milhões de hectares de terra. Desses, cerca de 6\% (3,6 milhões) são irrigados. Mesmo assim, essa atividade é responsável pelo consumo de $69 \%$ da água doce utilizada no Brasil.

No Estado do Ceará, a grande demanda do uso da água pela irrigação pode ser constatado também através de matéria de Jornal:

Considerando os consumos gerais em tempos normais, ou seja, sem grandes aportes ou seca extrema, $70 \%$ da água disponível no Estado vai para irrigação, algo em torno de $28 \%$ para abastecimento humano e saneamento e $2 \%$ pra todo o setor da indústria. Jornal O POVO . No Ceará 70\% da água do Estado vai para agricultura.31.05.2017.

A fruticultura irrigada se destaca nos projetos de Irrigação no Ceará com a produção de frutas para exportação que não prioriza a segurança e soberania alimentar, tendo sido esta garantida pela agricultura familiar. 
Uma das questões graves diz respeito a exportação de água e energia envolvidas na produção das frutas. Ademais, o capital internacional através de grandes empresas expropria terras há décadas nas mãos de comunidades tradicionais.

Com a mudança de direção da política agrícola agora voltada às fazendas-empresas, altamente competitivas e tecnificadas que tem grande parte de sua produção direcionada principalmente para o mercado externo, presencia-se na Chapada do Apodi uma fusão cada vez maior de capitalistas e grandes proprietários, pois as empresas agrícolas que aí se instalam passam a adquirir grandes extensões de terra de modo a tentar conseguir de forma direta a matéria-prima indispensável para a sua produção, quando então latifundiários e empresários se personificam numa só pessoa.

O nível de exploração tem levado muitos à expropriação e uma consequente proletarização. Verificamos em trabalho de campo no Baixo Jaguaribe inúmeros casos de irrigantes e filhos de irrigantes que perderam seus lotes de terra e para garantir o sustento da família passaram a vender sua força de trabalho. Acontece aqui aquilo que Kautsky (1986) afirma, pois a subordinação do agricultor se dá principalmente ao nível do fornecimento de força de trabalho através da sua expropriação.

Na segunda metade da década de 1990 já se evidenciava as dificuldades enfrentadas pelos irrigantes no Perímetro Irrigado Jaguaribe-Apodi ${ }^{2}$. Muitos destes irrigantes, endividados devido o elevado custo de manutenção do perímetro, que deixava de ser coberto a fundo perdido pelo Dnocs, tiveram que desistir de suas terras, repassando-as à empresários agrícolas.

Assim, se grande parte da pequena produção perde importância como ofertante de gêneros alimentícios, paralelamente ela ganha destaque como reservatório de braços para grandes proprietários ou empresas agrícolas.

Despossuídos dos meios de produção se submetem a todo tipo de situação, como as que presenciamos em campo, quais sejam: atraso de pagamento, aumento da jornada de trabalho, péssimas condições de trabalho (como falta de instalações sanitárias, água potável, inexistência de material de proteção como botas, luvas, bonés etc), trabalho sem registro em carteira, portanto privado dos direitos trabalhistas.

\footnotetext{
${ }^{2}$ Pode ser conferido os impactos dos perímetros irrigados no Ceará através do Dossiê(2014) em que foram realizadas coleta e organização de pesquisas científicas, textos e estudos de caso em cinco perímetros irrigados no Estado do Ceará e Rio Grande do Norte, tendo Raquel Rigoto como uma das profas à frente deste projeto. Dossiê(2014) https://dossieperimetrosirrigados.wordpress.com/ Pode ser conferido também o documentário Morte e Vida da chapada do Apodi.
} 
Revista de Geografia (Recife) V. 36, No. 2, 2019

Esta modernização da agricultura, embora alimente o comércio internacional e aumente divisas, ao promover mecanismos de apropriação desigual da terra e da água, impulsiona uma cadeia de transformações econômicas, ambientais, sociais e sanitárias que têm resultado na violação do direito à saúde e ao meio ambiente. Compõem ainda esta cadeia as dinâmicas de desqualificação dos modos de vida tradicionais, de precarização do trabalho e de geração de conflitos ambientais, que ameaçam a paz nas comunidades...

(https://www.researchgate.net/publication/314113598_Perimetros_Irrigados_E_Dire itos_Violados_No_Ceara_E_Rio_Grande_Do_Norte_Por_Que_A_Agua_Chega_E_

A_Gente_Tem_Que_Sair? [accessed Aug 30 2018]. Revista pegada. dez de 2016.

Somente a terra não resolve os inúmeros problemas enfrentados por estes agricultores, mas a posse da terra representa a segurança da família, sua continuidade no campo e as condições mínimas de consumo. Ademais, não ter acesso à terra significa também, não ter acesso a recursos financeiros para investimento na produção, "porque o banco financia quem tem terra, os que não têm terra é difícil conseguir o empréstimo, porque o banco exige o aval na hora que a gente vai atrás do dinheiro", relatou um agricultor durante pesquisa de campo.

... na medida em que matérias-primas, instrumentos de trabalho e meios de subsistência vão, progressivamente, se transformando em mercadoria. O produtor vai sendo colocado cada vez mais sob a dependência do mercado e, mesmo que ainda detenha a posse parcial e precária dos meios de produção, esta é mediatizada pela mercadoria e pelo capital... (SILVA, 1978).

Devido aos limites deste artigo não será possível tecer maiores considerações quanto as consequências do processo de modernização em curso no uso da terra e água que envolve também questões ligadas a impactos ambientais resultante de práticas inadequadas e contaminação do lençol freático, como também compactação de solos e perda de nutrientes básicos para produção saudável a longo prazo. Ademais o quadro de seca tem levado a dificuldades no crescimento do cultivo da fruticultura irrigada

As exportações cearenses têm recuado. Depois de alguns anos de seca, as exportações do agronegócio cearense caíram 11,64\% em relação ao ano anterior (2016). No ano de 2017 foram exportadas 208,545 mil toneladas, enquanto em 2016 foram 280,437 mil toneladas.

http://diariodonordeste.verdesmares.com.br/cadernos/negocios/exportacoes-doagronegocio-cearenses-recuam-.17 de janeiro de 2018.

Este quadro tem levado ao agravamento dos conflitos por água, pois enquanto agricultores foram desapropriados em áreas de implantação dos perímetros irrigados e os poucos que ainda resistem enfrentam dificuldades em manter os custos com o uso da água. As 
empresas que se instalaram nesses espaços de exceção elevaram a demanda por água e tem enfrentado também problemas de dimensão dispares com a escassez desta. Os conflitos pela água no Brasil dobraram na ultima década e a região Nordeste registrou o maior número em 2013. De um total de 93 no país, são 37 os conflitos conflitos contabilizados pela Comissão Pastoral da Terra (CPT). Este aumento dos conflitos por água no semiárido está relacionado, dentre outras coisas, à construção de barragens e à desigual distribuição deste recurso.

Por outro lado, tem se destacado na região o investimento na atividade de mineração, notadamente em Quixeré, com grande potencial de extração de minérios devido a grande quantidade de calcário. Ou seja, além da presença de grandes empresas transnacionais e nacionais, como as agroindústrias, Fruta Cor, Bananas do Nordeste S/A, Angel Agrícola e Del Monte FreshProduce. Os grupos Cimentos Apodi, Carbomil, Mizu Cimentos, Itatiba Mineração se fazem presente neste território. A instalação desses equipamentos tende a acentuar os impactos ambientais e sociais na região.

Ressaltamos que o âmago da política de irrigação orientada pelo processo de modernização com base na agricultura irrigada tem em seu segundo momento o agronegócio como carro-chefe.

Assim, tem início no final da década de 1980, a fase atual do processo de modernização da agricultura no Baixo Jaguaribe. O perímetro irrigado Jaguaribe-Apodi e o Tabuleiro de Russas se encaixam nessa nova forma de organização. Momento em que se convida o capital privado a participar da colonização, quando percebemos claramente uma separação entre a política de irrigação voltada para o pequeno produtor, da direcionada à agricultura empresarial conduzida de forma a estimular o agronegócio que vêm beneficiando um grande número de empresários e um diminuto grupo de pequenos produtores, contribuindo, assim, para a formação de uma classe de produtores rurais diferenciada que pode ser classificada de pequenos empresários agrícolas, um 'novo' ator da agricultura moderna, altamente tecnificado e conhecedor das regras do mercado.

Diferentemente da estrutura dos perímetros irrigados construídos na década de 1970 agora temos também áreas destinadas às empresas e na figura do "colono" não temos mais o pequeno produtor modernizado, mas um microempresário e no lugar das culturas voltadas para subsistência temos agora culturas com elevado valor comercial.

No Ceará, a ruptura política experimentada pelo Estado na passagem de 1986, para 1987 foi sem dúvida o marco político-institucional que permitiu renovar o discurso e a abordagem 
no tratamento aos efeitos da seca, bem como significou uma mudança de paradigma na condução das políticas públicas estaduais.

Durante o primeiro "governo das mudanças", entre 1987 e 1991, foram dados dois passos decisivos na direção da montagem do novo modelo de gestão dos recursos hídricos do estado. O primeiro passo foi de caráter institucional, e se deu pela criação da Secretaria dos Recursos Hídricos - SRH e da Superintendência de Obras Hidráulicas - SOHIDRA além da incorporação da FUNCEME ao sistema de recursos hídricos. O segundo passo foi de natureza técnica e estratégica e se deu através da elaboração do Plano Estadual de Recursos Hídricos - PERH.

Dentre as instituições que fazem parte da Secretaria de Recursos Hídricos (SRH) que representou um avanço no processo institucional de estadualização da oferta e gestão dos recursos hídricos temos a Companhia de Gestão dos Recursos Hídricos (COGERH) e os Comitês de Bacias Hidrográficas ensejando importante fórum para a participação da sociedade civil organizada na complexa questão da gestão integrada e sustentável dos recursos hídricos.

Em 1997, o Ceará tornou-se um dos estados brasileiros pioneiros no gerenciamento dos recursos hídricos, com a organização do primeiro Comitê de Bacia hidrográfica do nordeste, o Curu. Uma das funções dos Comitês é gerenciar de forma racional os recursos hídricos do Estado. Como os múltiplos usos da água geram interesses antagônicos devem ser bem administrados para evitar conflitos.

Mesmo diante destas mudanças com a modernização da agricultura, as teses levantadas durante o debate agrário dos anos 1950 e 1960 acerca da modernização mostram-se equivocadas. A modernização que se dá de forma pontual não eliminou as desigualdades que persiste até nossos dias e mesmo assim, o dito atraso e muito menos o latifúndio não são e nunca foram um empecilho ao desenvolvimento do capitalismo na agricultura.

Assim sendo, estas teses cedem lugar à forma como se deu as transformações na agricultura para que esta respondesse às necessidades do processo de desenvolvimento industrial passando a ser denominada de modernização desigual (GONÇALVES NETO, 1997), conservadora (SILVA, 1978, 1999; DELGADO, 1985), dolorosa (SILVA, 1996), incompleta e parcial (MULLER, 1989; SILVA, 1981, 1996), como também, extremamente seletiva (THOMAZ JR, 2000) e excludente (ELIAS, 1999, 2002).

\section{Considerações Finais}

As denominações da forma como vem se dando a modernização na agricultura se explica pelo fato de que as mudanças no processo de produção resultaram em aumento da produção, 
produtividade e rentabilidade, mas essas benesses não se fizeram acompanhar por uma distribuição equilibrada, intensificando as desigualdades sociais já existentes, contribuindo, assim, para acelerar e perpetuar uma estrutura social marcada por um processo de acumulação, concentração e centralização da renda e do poder nas mãos de uma minoria, na qual ingressam cada vez mais, grandes empresas nacionais e transnacionais. Estas denominações também expressam o fato de que a modernização é fruto do processo de expansão capitalista no campo brasileiro, e como tal, não homogeneiza os espaços, pelo contrário, desenvolve-se contraditoriamente provocando geografizações diversas ao privilegiar espaços seletos e não atingir igualmente, nem ao mesmo tempo, produtos e produtores.

A modernização ocorreu de forma heterogênea, descontínua no tempo e no espaço, sendo que onde a integração ao processo mais amplo de acumulação capitalista ocorreu de forma acentuada, atingiu principalmente as atividades intensivas de capital e algumas fases do ciclo produtivo.

A modernização da agricultura Cearense com a implantação do agronegócio da fruticultura irrigada e abertura ao mercado mundial tem trazido inúmeras consequências, dentre as que pudemos evidenciar neste artigo, além das de ordem social, territorial e ambiental, as atinentes a crescente demanda por recursos hídricos que somado a escassez tem agravado os conflitos no tocante à distribuição e uso da água, sem esquecer também os conflitos por terra e a intensificação da histórica concentração de terra, renda e poder. Eis o desafio que é posto para toda a sociedade na busca pela mediação destes conflitos e uma verdadeira mudança na estrutura agrária que venha considerar as relações entre os desiguais e proporcionar meios para que a população economicamente mais vulnerável venha a ser incluída no usufruto das benesses que atende aos anseios de uma minoria.

\section{Referências}

BARREIRA. César, e PAULA. Luiz Antônio M. de. A luta pela terra no Ceará, Assentamentos rurais no Ceará... In: SCHMIDT, B. MARINHO. Danilo C. e ROSA. Sueli L. Couto (orgs.). Cadernos Conflitos no Campo da CPT. Brasília: Ed. Universidade de Brasília, 1998.

COMISSÃO PASTORAL DA TERRA. Conflitos no campo Brasil 2016. CPT Nacional, Gioânia, 2017.

DELGADO, Guilherme da Costa. Capital financeiro e agricultura no Brasil. Campinas: Unicamp / Icone, 1985.

ELIAS, Denise. A Agropecuária do Estado do Ceará no Contexto da Globalização. In: AMORA, Zenilde Baima (org). Ceará: Enfoques Geográficos. Fortaleza: Funceme, 1999. 
ELIAS, Denise e SAMPAIO, José Levi Furtado. (orgs). Modernização Excludente. Fortaleza: Fundação Demócrito Rocha, 2002. (Coleção Paradigmas da Agricultura Cearense).

GONÇALVES NETO, Wenceslau. Estado e agricultura no Brasil: política agrícola e modernização econômica brasileira 1960-1980. São Paulo: Hucitec, 1997.

KAUTSKY, Karl. A questão agrária. São Paulo: Nova Cultural, Proposta Editorial, 1986.

LIMA, Silvana Lúcia da Silva. As políticas públicas e a modernização agrícola do Baixo Jaguaribe Ceará. Fortaleza, Universidade Estadual do Ceará, 2000. (Dissertação de Mestrado em Geografia).

MATOS, Helaine Saraiva; ALENCAR, Francisco Amaro Gomes de. CONFLITOS E VIOLÊNCIA NO ESPAÇO AGRÁRIO BRASILEIRO DE 1985-2013: CONSIDERAÇÕES SOBRE OS CONFLITOS EM TEMPOS DE SECA NO NORDESTE. GEOSABERES: Revista de Estudos Geoeducacionais, v. 6, p. 149-159, 2016.

MULLER, Geraldo. Complexo agroindustrial e modernização agrária. São Paulo: Hucitec: educ. 1989. (coleção Estudos Rurais).

MUNIZ, Alexsandra M. Vieira. Reestruturação produtiva e trabalho agrícola no Baixo Jaguaribe. Dissertação (Mestrado) - Universidade Federal do Ceará, Fortaleza, 2004.

SAMPAIO, J. L. F.; RAFAEL, Francisco Levy Freitas. Conflitos por terra no Ceará: 20102015. XIIIENGA 2016.

SILVA, José Graziano da. Estrutura Agrária e Produção de Subsistência na Agricultura Brasileira. São Paulo: Hucitec, 1978.

Progresso Técnico e Relações de Trabalho na Agricultura. São Paulo: Hucitec, 1981.

Passos).

O que é questão agrária. $18^{a}$ ed. São Paulo: Brasiliense, 1994. (Coleção Primeiros

\section{6.}

. A Nova Dinâmica da Agricultura Brasileira. Campinas, São Paulo: UNICAMP/ IE,

SORJ, Bernardo. Estado e Classes Sociais na Agricultura Brasileira. Rio de Janeiro: Zahar, 1980.

THOMAZ JÚNIOR, Antônio. Por uma geografia do trabalho. IV Colóquio Internacional de Geocrítica, Barcelona, 2002. www.ub.es/geocrit/c4-athoj.htm 